\title{
AGAMA DAN MITOS: \\ Dari Imajinasi Kreatif Menuju Realitas yang Dinamis
}

\author{
Roibin \\ Fakultas Syari'ah, Universitas Islam Negeri Malang, Gedung Sport Centre It.1, Jalan Gajayana 50 Malang \\ 65144 Telp. 08179604562. e-mail: roy.uin@yahoo.co.id
}

\begin{abstract}
Myth always comes to be a debatable discourse among the scholars and observers of Islam. Frequently, a scientific study of myth leads to an extreme ideological analysis. From the debates, the side that is in favor of religion is system atically typed into pro and contra. The pro-myth side always says that myth is spirit of life that can arouse the vitality in real life. While, the negative side says that myth merely abstracts the concrete things. In other words, the pro side says that myth concretizes the abstract things, while the contra side is the opposite. From the different perspective, this writing intentionally uncovers their academic-philosophical reasons and identifies the reason why they think so. The questions are expected to reveal the sociological background of each initiator of the concept and theory of myth.

Key words: myth, imagination and reality
\end{abstract}

\section{Pendahuluan}

Mitos berasal dari bahasa Yunani muthos, yang secara harfiah diartikan sebagai cerita atau sesuatu yang dikatakan seseorang. Dalam arti yang lebih luas, mitos berati pernyataan, sebuah cerita atau alur suatu drama. Lebih spesifik, Malinowski membedakan pengertian mitos dari legenda dan 
dongeng. Bagi Malinowski, legenda merupakan cerita yang diyakini yang seolah-olah merupakan kenyataan sejarah; sedangkan dongeng mengisahkan peristiwa-peristiwa ajaib tanpa dikaitkan dengan ritus (Dhavamony, 1995: 147). Mitos dalam kaitannya dengan agama menjadi penting bukan sematamata karena memuat hal-hal gaib atau peristiwa-peristiwa mengenai makhluk adikodrati, melainkan karena mitos tersebut memiliki fungsi eksistensial bagi manusia dan karenanya mitos harus dijelaskan menurut fungsinya (Dhavamony, 1995: 150).

Fungsi utama mitos bagi kebudayaan primitif adalah mengungkapkan, mengangkat, dan merumuskan kepercayaan, melindungi dan memperkuat moralitas, menjamin efisiensi ritus, serta memberikan peraturan-peraturan praktis untuk menuntun manusia (Malinowski, 1954: 101). Mitos, pada satina, betul-betul berperan sebagai peran agama, mengingat masih sederhananya konsepsi agama ketika itu di kalangan komunitas primitif. Mitos pada saatnya mengandaikan suatu ontologi dan hanya berbicara mengenai kenyataan, yakni apa yang sesungguhnya terjadi. Mircea Aliade mengartikan bahwa mitos adalah sebagai kenyataan yang suci. Kesucian sebagai satu-satunya kenyataan tertinggi. Kenyataan sesungguhnya, penuh dengan adanya (Dhavamony, 1995: 152).

Mitos tidaklah sebagaimana pandangan di atas, mitos menurutnya adalah kata kiasan yang indah dan fantasi (khayal), bersayap atau kisah yang indah yang memiliki inti dalam realitas. Mitos, bagi Arkoun, tidak selalu terkait dengan agama. Mitos merupakan langit yang membentang yang memayungi keberadaan dan memberikan makna kepadanya. Ia merupakan impian-impian kebajikan abadi dan fantasi segar yang membangkitkan vitalitas dalam realitas (wujud) dan mengeluarkan kita dari kepekatan dan desakan realitas. Membawa kita kepada langit-langit yang bening, ideal dan indah (Arkoun, 1999: 112).

\section{Fungsi Agama, Mitos dan Mitologi}

Dilihat dari sisi fungsinya, menurut Arkoun mitos berperan sebagai layaknya fungsi agama; namun, tidak menggantikan agama itu sendiri. Dikatakan demikian karena mitos adalah impian-impian kebajikan universal yang berperan sebagai sumber nilai yang bisa dijadikan pedoman bagi kehidupan mereka. Sementara konsepsi-konsepsi agama yang tertuang dalam teks suci juga selalu memuat impian-impian ideal yang indah itu. 
Impian-impian indah itu misalnya tentang gambaran indahnya surga, yang di bawahnya mengalir air sungai, di dalamnya terdapat rizki atau buah-buah serta istri-istri yang suci (bidadari) (al Baqi, 1945: 12; 231). Perbedaan keduanya hanya terletak pada subjek yang melakukan konstruksi atas impian ideal itu. Subjek konstruksi mitos adalah manusia, sedangkan subjek konstruksi agama adalah dua kekuatan kompromistik antara Tuhan sebagai representasi wahyunya dan manusia sebagai representasi hasil penafsirannya.

Dalam kondisi seperti ini, manusia tidak akan mampu hidup tanpa agama, demikian juga tanpa mitos, sekalipun ia selalu mengalami perubahan dari zaman ke zaman dan dari generasi ke generasi. Perubahan tersebut, baik agama maupun mitos karena atas tuntutan situasional dan kondisional yang menyertainya. Atas dasar itu mitos Tunisia, sebagai contoh bukanlah mitos pada masyarakat Perancis. Artinya mitos pada masyarakat agraris yang sama sekali belum memasuki tahapan masyarakat industri bukanlah mitos yang ada pada masyarakat post-industri dan post-modern (Arkoun, 1999: 113).

Keadaan inilah yang membuat Arkoun menjadi optimis akan nilai fungsi mitos itu. Mitos memiliki pemahaman yang sangat berbeda dengan mitologi. Dalam pandangan Arkoun mitos dan mitologi adalah dua kata yang memiliki perbedaan mendasar. Perbedaan itu tidak terletak pada jenisnya, namun pada tingkatannya. Bagi Arkoun ketika mitos telah runtuh dan merosot maka mitos itu telah berubah menjadi khurafat (mitologi) yang tidak memiliki nilai, sekalipun ia tetap tertanam kuat dalam kesadaran populisme suatu bangsa atau kelompok. Disanalah mitos menurut Arkoun memiliki makna positif dengan mengisi tekad dalam cita-cita dan mendorong ke arah kemenangan dan realisasi diri di atas bumi ini. Sementara itu mitologi menurutnya hanya akan melemahkan tekad dan menyerukan sikap santai, puas dan menyerah terhadap dekapan fanatisme yang telah lama sakit dan tidur di atas sejarah. Mitos yang telah usang akan melahirkan khurafat (mitologi). Dalam hubungannya dengan konteks modern ini penggambaran keilmuan bagi realitas telah menggantikan posisi mitos, sementara ideologi atau paham (dalam arti negatif) telah menggantikan posisi mitologi (Arkoun, 1999: 113).

Dengan kata lain, mitos sebagaimana pandangan Arkoun senantiasa mengidealkan adanya pembaruan-pembaruan sesuai dengan tingkat perkembangan zamannya. Sekali saja ia kehilangan daya aktualnya maka ia tidak memiliki kemampuan untuk membangkitkan nilai fitalitas masyarakatnya. 
Semangat nilai konstruksi mitos tidak akan lepas dari latar sosio-kultural dari pengkonstruk mito itu sendiri, tergantung dimana, kapan mitos itu di konstruksi. Dengan begitu bisa dipahami bahwa karakteristik mitos yang berkembang di masyarakat Jawa, tentu tidak jauh dari keyakinan dan kepercayaan kejawen itu. Demikian juga mitos yang berkembang di Lombok, Sulawesi, Ambon dan tempat yang lainnya , semuanya tidak akan lepas dari karakter dasar kondisi lokalitasnya.

\section{Dimensi-Dimensi Mistis dalam Islam}

Mitos yang dikonstruksi di tengah-tengah kehidupan masyarakat agama acapkali juga akan menampakkan nilai-nilai agamis. Sebut saja misalnya, munculnya hadits terkait dengan kemuliaan air zamzam bahwa ia berasal dari surga, (al Imam Muslim, Shahih, 2183: IV) termasuk juga hadis lain yang senada yang menyatakan bahwa air zamzam itu penuh berkah, air itu mengenyangkan dan dapat menyembuhkan penyakit (Bakdasy, 2002: IX). Kedua-duanya adalah sabda Rasul yang tidak terlepas dari kemampuan Rasul dalam mengimajinasikan kemuliaan zamzam tersebut. Karena itu hadits tersebut adakalanya tampil sebagai representasi ajaran; namun, disi lain ia adalah representasi daya khayali Rasul yang disebut mitos.

Kisah lain yang bernada mitis dijumpai pula di kalangan para Sahabat dan Tabi'in. Syaiban an Nakhai (tabi'in), misalnya, ia ketika berangkat bersama para muhajirin untuk melakukan jihad, tiba-tiba keledainya mati. Teman-temannya mengajak agar meneruskan perjalanan bersama mereka dengan jalan menumpang keledai mereka. Namun, ia menolak seraya berdo'a:Ya Allah, aku berangkat dari Daitsanah untuk berjalan di jalan-Mu dan mencari keridhaan-Mu. Aku bersaksi bahwa engkau kuasa menghidupkan orangorang yang mati dan membangkitkan kembali orang-orang yang ada dalam kubur. Ya Allah tolong hidupkan kembali keledaiku. Usai berdo'a ia menghampiri keledainya dan memukulnya, seraya keledai itu langsung bisa berdiri dan menggerak-gerakkan telingannya (Ibad, 2007: 216).

Dalam kisah lain Abu Yusuf ad Dahmani pernah bercakap kepada mayat dan berkata: "Berdirilah!" Seketika itu juga mayat tersebut berdiri dan hidup dalam waktu yang cukup lama. Syeikh Zaenuddin al-Faruqi juga pernah berdo'a kepada Allah agar menghidupkan kembali seorang anak kecil yang mati karena terjatuh dari loteng, dan Allah pun mengabulkan. Syeikh Muhammad Bahaudin an Nakhsyabandi pernah menghidupkan temannya, 
Muhammad Zahid yang seharian telah meninggal dunia. Beliau juga punya pengalaman untuk memanggil seorang keluarga santrinya yang telah mati yang berada di Bukhara, tiba-tiba Syamsuddin yang telah meninggal tersebut hadir di depan Syaikh tersebut. Termasik juga kisah Sunan Ampel yang pernah memanggil mbah Shaleh yang telah meninggal lama untuk kembali membersihkan masjid karena tidak ada santri yang mampu membersihkan masjid sebersih dia (Ibad, 2007: 217-218).

Kisah di atas secara teologis tidak bertentangan dengan ajaran agama Islam, Namun, ketika dilihat dari substansinya, isi cerita itu mengandung muatan mitologis bagi generasi yang meyakini setelahnya. Dalam kenyataan riil di masyarakat kisah itu tiba-tiba menjadi sebab munculnya mitologi baru yang sakral. Karena secara normatif, keyakinan mereka tertuju kepada para syaikh dan bukan kepada Tuhan mereka. Sikap seperti inilah yang membuat mereka diklaim sebagai pelaku bid'ah, khurafat dan tahayu, Karena mereka telah meyakini secara berlebihan berbagai kemulyaan yang dimiliki para wali, termasuk syeikh. Hanya saja, pertanyaannya apakah benar bahwa perilaku itu sebagai perilaku bid'ah? Tentu saja dalam menilai perilaku itu tidak cukup hanya dengan cara mengklaim dari jarak jauh, dan menyimpulkan bahwa perilaku tersebut adalah menyimpang, tetapi memerlukan pengamatan lebih detil dan akurat. Karena itu tidak ada jalan lain kecuali dengan menelitinya secara objektif.

Demikian juga bacaan-bacaan asma dengan serentet tata aturan serta khasiatnya, do'a-do'a ghairu ma'tsur dengan sejumlah aturan dan maksud serta tujuannya, hizib dengan tata cara mengaplikasikannya, bacaan-bacaan wirid serta kegunaannya, termasuk bagaimana tata cara membuat rajah. Dalam konteks pesugihan (ekonomi), misalnya, baik dalam kitab Syamsul Ma'arif alKubro, Mamba'u al-Hikmat maupun Dalailu al-Khairat secara spisifik mengenai bab-bab kajiannya telah diajarkan dengan mendetail. Misalnya, bab yang terkait dengan cara mudah mendatangkan rizki, diperluas rizkinya hingga menjadi kaya, supaya diberi perkembangan rizki yang banyak, supaya sangat mudah rizkinya dan dihilangkan kepayahan sehari-hari dalam mencari rizki, supaya diberi harta banyak dengan pekerjaan yang mudah, supaya menjadi mulia dan bahagia, supaya tidak pernah kekurangan rizki, supaya tidak menjadi fakir selamanya, supaya tidak kesusahan dan prihatin masalah rizki, supaya cepat laku dagangannya dengan keuntungan yang banyak, supaya laris tokonya, sukses kebutuhannya (Sunarto, 1990: 242-252).

el-Harakah, Vol. 12, No.2, Tahun 2010 
Kenyataan ini semua menunjukkan bahwa cikal bakal tradisi mitis, magis dan mistis telah berkembang lama di kalangan Islam. Apa yang dilakukan oleh Rasul, Sahabat, ulama dan kyai di kalangan masyarakat muslim umumnya, pada hakikatnya juga upaya konkretisasi dari nilai-nilai abstrak tersebut. Termasuk juga mitos yang dipahami Arkoun di atas tidak lain adalah upaya-upaya konkretisasi dari hal-hal yang bersifat abstrak, dari impian menuju kenyataan.

\section{Pemahaman Mitos di Kalangan Para Pemikir Muslim dan Non Muslim}

Tidak semua pemikir setuju dengan cara pemahaman Arkoun. Bahkan, sebagian kalangan menilai sebaliknya, bahwa mitos itu selalu berkonotasi negatif. Kuntowijoyo dengan memakai kaidah cara berpikir mitosnya mengatakan bahwa mitos itu hanya akan melahirkan abstraksiabstraksi dari yang konkret. Inti dari pemikiran Kunto yang paling dalam tersebut mengatakan bahwa mitos itu harus dihindari karena tidak kongkrit (Kuntowijoyo, 2002: 96-97). Masih dalam pandangannya, mereka yang hidup dalam mitos tidak akan bisa menangani realitas (Kuntowijoyo, 2002: 97).

Cara pandang Kuntowijoyo di atas jika dikritisi dengan pendekatan ilmiah terkesan tidak akademis, sangat peyoratif, dan normatif. Kekhawatiran Kuntowijoyo tentang mitos sama artinya kekhawatiran Arkoun tentang mitologi. Pemahaman Kuntowijoyo tentang mitos -jika dilihat dengan pemikiran Arkoun- telah terjebak dengan pemahaman mitologi. Sudah barang tentu, jika yang dimaksud mitos oleh Kuntowijoyo adalah mitologi menurut Arkoun, maka benar ia tidak memiliki kemampuan untuk membangkitkan vitalitas dalam realitas.

Endraswara berpandangan bahwa mitos diartikan sebagai cerita-cerita suci yang berbentuk simbolik yang mengisahkan serangkaian peristiwa nyata dan imajiner menyangkut asal-usul dan perubahan alam raya dan dunia, dewa-dewi, kekuatan atas kudrati, manusia, pahlawan dan masyarakat. Karenanya, ketika mitos dalam konteks pemahaman Kuntowijoyo, cenderung dimaknai sebagai hal yang negatif, mitos tidak dilihat dari kaca mata pendekatan ilmu, tetapi lebih dilihat dari kacamata nalar agama yang terikat secara subjektif terhadap kecenderungan untuk menilai, menghakimi, yaitu positif dan negatifnya, boleh dan tidak bolehnya, bahaya dan tidaknya mitos tersebut diyakini, tanpa melihat makna mitos secara ilmiah dan alamiyah, apa maksud dan bagaimana praktik mitos itu. 
Pada sisi lain, mitos merupakan suatu warisan bentuk cerita tertentu dari tradisi lisan berdasarkan suatu skema logis yang terkandung di dalam mitos itu dan yang memungkinkan mengintegrasikan semua masalah yang perlu diselesaikan secara sistematis. Namun demikian ia seringkali dipahami sebagai cerita aneh dan mustahil yang sulit dipahami maknanya. Mitos terkadang disebut sebagai cerita tidak teratur, namun ketidakteraturannya terdapat keteraturan yang tidak disadari oleh penciptanya. Endraswara mengatakan bahwa mitos di Jawa memang banyak ragamnya, antara lain mitos gugon tuhon, yaitu mitos larangan-larangan tertentu, mitos bayangan asosiatif, mitos berupa dongeng dan mitos yang berupa sirikan (yang harus dihindari).

Dalam konteks yang hampir sama, Kirk berhasil membuat tipologi mitos dan fungsinya dalam perkembangan kebudayaan. Menurut Kirk ada tiga tipologi mitos dan fungsinya dalam perkembangan masyarakat, yaitu 1). Mitos naratif yang berfungsi menghibur. 2). Mitos operatif, mitos yang diulang-ulang dimaksudkan untuk hal-hal yang bersifat megis, ritual dan untuk menghasilkan suatu kontinuitas yang diinginkan. 3). Mitos eksplanatoris dan spekulatif, yaitu fungsi yang jauh lebih luas dari hanya sekedar cerita (Kirk, 1983: 258).

Tidak kalah pentingnya Dhavamony telah mengurai secara luas macammacam mitos. Pertama: mitos penciptaan, yaitu mitos yang menceritakan alam semesta yang sebelumnya tidak ada. Kedua: mitos kosmoginik, mitos yang mengisahkan penciptaan alam semesta dengan menggunakan sarana yang sudah ada. Ketiga: mitos asal-usul, mitos yang mingisahkan asal mula atau awal dari segala sesuatu. Keempat: mitos mengenai para dewa dan mengenai makhluk adikodrati. Kelima: mitos yang terkait dengan kisah penciptaan manusia. Keenam: mitos yang berkenaan dengan transportasi.

Dengan cara pemahaman seperti ini, secara ontologis maupun epistemologis, proses dan pengalaman bagaimana komponen-komponen serta konstruks mitos itu dibangun akan diketahui dan dipahami. Apakah mitos itu dibangun atas kerangka konsep kosmologi masing-masing situasi, ataukah dibangun atas dasar kepentingan-kepentingan tertentu, atau sebagai representasi agama, sehingga ia selalu sarat dengan makna?

Secara umum mitos selalu dihubungkan dengan masyarakat mistis, namun demikian tidak berarti masyarakat modern telah meniadakan mitos ini sama sekali. Tidak sedikit masyarakat modern yang masih mempercayai 
adanya warisan kuno, warisan spiritual. Stanley R. Barret dalam bukunya "The Rebirth of Anthropological Theory" mengupas secara detil tentang teori mitos. Mitos menurut perasaan non teknis dianggap sebagai kepercayaan palsu, terkadang dipahami sebagai persoalan yang salah dan persoalan yang tidak berwujud. Namun demikian hingga kini mitos merupakan salah satu isu akademik yang tetap hangat, utamanya dalam hal penafsiran kejadiankejadian sejarah. Oleh sebab itu mitos menurut Barret adalah dokumentasi masyarakat yang tidak ditulis dalam sejarah. Mitos juga sering berfungsi untuk memberikan penjelasan tentang asal kedatangan suku maupun kelompok etnik, dari sisi tempat maupun asal kehidupannya. Mitos juga berfungsi sebagai solusi dalam kehidupan yang mendasar, selain itu mitos juga sebagai sumber kekuatan psikis manusia.

Pada hakikatnya mitos selalu muncul dalam ranah psikis manusia. Karena itu menurut Jamhari mitos tergantung kepada model pengartikulasian intelektual primordial dari kepercayaan itu. Pada gilirannya mitos juga tergantung kepada keputusan subjektif penghayatnya. Mitos berarti suatu sikap keagamaan atau merupakan filsafat primitif, pengungkapan pemikiran yang sederhana, serangkaian usaha untuk memahami dunia, untuk menjelaskan kehidupan dan kematian, takdir dan hakikat, tuhan dan pemujaan (Djamhari, 1988: 35).

Berangkat dari pernyataan subjektif itu mitos juga dipahami sebagai pernyataan manusia yang kompleks dan dramatis, yang melibatkan pikiran, perasaan, sikap dan sentimen. Ia berada di luar dunia empirik, tetapi selalu mengaktualkan apa yang telah dikisahkan.

Aktualisasi kisah suci yang diakui kebenarannya itu, dalam realitas sosial selalu berjalan secara ajeg dalam bentuk ritual. Pelaksanaan ritual dalam agama primitif kuno, pada hakikatnya upaya menyatukan antara aku dan manusia dengan objek suci. Hanya saja jalan pemikiran keagamaan mereka selalu didorong untuk mempersonifikasikan dan melambangkan "dia" dengan lambang-lambang yang dinilai bisa menjadi perantara. Lambang itu adakalanya berwujud alam semesta ini (langit dan bumi), roh halus atau arwah nenek moyang yang mereka gambarkan sebagai tuhannya (Subagya, 1981: 70-71). Sementara itu, ritual yang mereka lakukan tidak terlepas dari relasi alam, yaitu agar alam ini tidak murka, alam yang melambangkan Tuhan (Hayat, 2003: 155). Betapapun corak manusia primitif kuno yang telah dikaji oleh Muhammad Hayat ini, ternyata dalam banyak dimensi juga masih memiliki keyakinan mitis 
tentang adanya Tuhan, sebagaimana layaknya ajaran-ajaran agama besar dunia. Bila kita mengamati tradisi ritualitas masyarakat secara sederhana di manapun mereka berada, di balik itu mereka pasti mendambakan adanya keteraturan dan terhindar dari marabahaya. Bagi mereka, kebutuhan agar mereka tetap hidup yang bisa menyediakan adalah alam. Dengan kata lain ritualitas adalah tindakan keseimbangan antara diri dengan alam (Hayat, 2003: 155). Oleh karena itu secara umum masyarakat primitif didominasi oleh mitos tentang kemurkaan alam. Agar alam tidak murka, maka kesepakatan yang mereka putuskan selalu berhubungan dengan kelestarian alam (Hayat, 2003: 156).

Atas dasar itu, Armada Riyanto memahami mitos sebagai ekspresi yang hidup mengenai relasi manusia dengan ruang lingkupnya dan keseluruhan lingkup hidupnya. Sementara itu Peursen juga mengatakan bahwa mitos adalah cerita yang memberikan pedoman dan arah tertentu pada kelompok pendukungnya. Tentu saja pedoman dan arah yang dimaksud dalam hal ini adalah bagaimana membangun hubungan relasional antara diri dan alam. Oleh karena manusia dulu membuat cerita maupun lambang yang mampu mencetuskan lambang kebaikan maupun kejahatan melalui mitos (Riyanto, 2002: 1).

Dengan demikian mitos merupakan medium yang netral, tergantung kepada misi dan visi pesan-pesan yang hendak disampaikan. Adakalanya berupa pesan-pesan politik, demikian juga pesan-pesan agamis dan moral. Dengan demikian mitos yang dibangun oleh lingkungan istana tentu akan berbeda pesan-pesannya dengan mitos yang dibangun oleh lingkungan wong cilik (pedesaan). Bagaimanapun lingkungan budaya istana kejawen tetap mempertahankan falsafah "raja titisan dewa" dengan mitologi kuno warisan zaman Syiwa-Budha. Oleh karena itu praktek mitologis tentang Nyai Rara Kidul, pusaka yang dikeramatkan dan upacara tradisional masa lalu, bisa jadi ditafsirkan sebagai medium politis yang amat efektif untuk melanggengkan wibawa kerajaan Jawa tradisional. Melalui cara ini pula kelanggengan dan kewibawaan warisan Hindu-Budha kejawen tetap terasa hingga kini, meski kekuatan mitologi Islam tetap bersaing.

Atas dasar misi ini pulalah Sultan Agung tetap memilih tahun satu saka sebagai pangkal perhitungan tahun Jawa, meski dasarnya telah digubah dengan tahun qamariyah. Kuatnya pengaruh mitos itu bisa disaksikan misalnya, pada pola budaya Islam kejawen hingga zaman Mataram. Pola budaya islam kejawen itu dalam kenyataannya tidak mengalami perubahan 
yang signifikan, bahkan ia seperti pola budaya kejawen pada zaman HinduBudha (Riyanto, 2002: 95).

Secara formal, agama memang mengalami perubahan, yaitu dari Hindu-Budha kejawen beralih ke Islam kejawen. Sementara konsep manunggaling kawula Gusti tak lebih dari sekadar dasar filsafat kebatinan yang dimanfaatkan untuk kebutuhan politik juga, yaitu memitoskan raja dan mengkeramatkan kalangan priyayi yang mendukung dinastinya. Bukti argumentasi ini bisa dikonfirmasikan pada suatu kenyataan bahwa belum ada di kalangan tokoh priyayi Jawa yang sekaliber al Hallaj. Tidak ada tokoh wali yang muncul dari keluarga Mataram kecuali cerita rekaan tentang Siti Jenar. Hal ini terlihat jelas melalui kemunculan tarikat kebatinan pada zaman kemodernan Indonesia dewasa ini. Dalam berbagai macam tarikat kebatinan itu, dimensi politislah yang paling dominan, sementara aspek penghayatan terhadap mitos manunggaling Kawula Gusti justru semakin lemah (Riyanto, 2002: 95-96).

Bentuk-bentuk mitos ini tidak sedikit berasimilasi dalam peringatan hari-hari besar Islam, seperti garebeg Maulud, garebeg pasa, garebeg besar, tanggap warsa. Koentjoroningrat mengatakan bahwa pada tanggal 12 bulan Maulud orang memperingati hari wafat dan hari lahirnya Nabi Muhammad (muludan). Baik para penduduk desa maupun para priyayi di kota-kota yang menganut "agami jawi" mereka mengadakan selamatan sekitar tanggal 12 Maulud tersebut. Hidangan pertama pada perayaan Maulud itu adalah tumpeng dan ayam yang dimasak dengan bumbu-bumbu dalam keadaan utuh (dibuang bulunya dan dibuang isi perutnya). Hal serupa juga terjadi di Surakarta dan Yogyakarta, mauludan dirayakan dengan mengadakan pesta sekaten dan upacara kerajaan garebeg Maulud (Riyanto, 2002: 95). Tradisi ritual Islam di atas betapapun juga telah menggambarkan terjadinya proses kolaborasi dan asimilasi terhadap budaya lokal Jawa yang tidak bisa dihindari. Perpaduan aspek Islam dengan alam pikiran tradisi lama, seperti pengkeramatan acara selamatan merupakan aspek sosio-religius yang sangat efektif yang sulit dihindari oleh masayarakat kejawen. Karena itu wajar jika Koentjoroningrat menamakan sebagai agama jawi. Praktek mitologi seperti ini semakin lama semakin kokoh karena secara periodik perilaku mitos ini diperkuat dengan ritualitas-ritualitas tertentu. Tentu aktor yang paling diuntungkan dalam upacara ritual keagamaan seperti ini adalah para elit, baik elit pemerintahan maupun elit agama. 
Bagi masyarakat pedesaan tradisional adat istiadat keagamaan memiliki daya pengikat tersendiri. Meninggalkan tradisi berarti mengancam kelanggengan eksistensi masyarakatnya. Islam yang hidup dalam masyarakat tertentu harus mampu bergulat dengan adat istiadat tradisional yang pada umumnya bersendi pada kepercayaan mitologis. Dalam pergulatan ini sangat mungkin unsur-unsur Islam dihilangkan untuk ramuan tradisi budaya. Mungkin pula Islam ditumpangi oleh unsur tradisi lama. Inilah makna simbolik dari aspek mitologis yang sangat politis. Namun demikian tidak tertutup kemungkinan munculnya beberapa penafsiran mitologis dalam tradisi Jawa ini yang mengarah pada aspek moralitas.

Oleh karena itu, bagi Edward B. Tylor, mitos seharusnya tidak ditafsirkan dengan cara penafsiran yang salah, tetapi ia adalah cara pandang yang mendalam dan filosofis tentang dunia. Sejak itulah mitos bagi pandangan Tyler tidak bisa ditolak sebagai persoalan yang salah maupun yang tolol. Lebih dari itu mitos menurutnya harus dikaji sebagai produk yang menarik dari pandangan manusia (Bell, 1997: 4). Karena itu, mitos menurut Parcy S. Cohan dipahami sebagai cerita tentang peristiwa awal mula dan transformasi termasuk di dalamnya tentang Tuhan, dewa dan dewi, yang mempunyai kualitas sakral yang penyampaiannya dalam bentukbentuk simbolis (Cohan, 1969: 337). Dalam literatur lain Molinowski juga mengatakan bahwa mitos bukanlah sesuatu yang bersifat simbolis belaka, melainkan suatu penggambaran sesungguhnya yang langsung tentang pokok permasalahannya (Malinowski, 1954: 101).

\section{Simpulan}

Dari sekian perspektif antropologis, baik dari kalangan Barat maupun Islam mengenai pemahaman mitos di atas, bisa ditarik benang merahnya bahwa mitos adalah bagian penting yang tidak bisa dipisahkan dari kehidupan manusia. Ia muncul sebagai keniscayaan psikis manusia karena dihantui oleh kekhawatiran-kekhawatiran, ketakutan-ketakutan akan murkanya alam semesta (Cosmos). Alam semesta dipersonifikasikan sebagai Tuhan yang sempurna, melindungi, mengayomi dan mengatur. Kemurkaannya akan bisa membuat dunia ini chaos, yaitu hancur berantakan yang berakibat pada kehancuran manusia. Agar kemurkaan itu tidak terjadi, maka manusia berusaha membangun keyakinan (myth), hubungan relasional antara dirinya dengan Tuhan dengan cara membuat renungan-renungan 
filosofis terhadap makna dunia. Proses relasional antara diri dan Tuhan itu akan terbangun secara sakral dan suci setelah manusia melakukan ritual, yaitu artikulasi-artikulasi intuitif, mitis, magis dan mistis terhadap hakikat di balik yang simbol itu secara intens. Dengan kata lain, sedikit, seandainya ada, ritual-ritual yang dilembagakan tanpa dasar mitos untuk mempertanggungjawabkannya. Karena itu mitos tanpa ritus, sama artinya dengan iman tanpa islam, sebaliknya ritus tanpa mitos, berarti amal yang telah kehilangan dasar pijakannya.

Kajian mitos ini menghasilkan kesimpulan bahwa dalam kajian agama apapun, formal atau non formal, besar atau kecil akan senantiasa melalui mekanisme relasionalistik dan tahapan-tahapan sistematik antara Cosmos, Chaos, Myth dan Ritual. Dengan kata lain agar manusia tetap terhindar dari musibah (chaos), selanjutnya berada di dalam keteraturan dan kedamaian (cosmos), maka manusia membangun cerita suci dan sakral tentang objek yang mengatur jagad raya ini yang diperkuat dengan upacara-upacara (ritual).

\section{Daftar Pustaka}

Arkoun, Muhammed. 1999. Membongkar Wacana Hegemonik dalam Islam dan Post-Modernisme. Diterjemahkan oleh Hasyim Shaleh. Surabaya: al Fikr.

Al Baqi, Muhammad Fu'ad Abdu. 1945. Al Mu'jam al Mufahras Lialfadi al Qurani al Karimi .Indonesia: Maktabat Dahlan.

Al Imam Muslim. 2002. Shahih, "Kitab al-Jannah”, Bab " Ma Fi al Dunya Min Anhari al Jannah". IV: 2183.

Al Bukhari. 2002. Shahih Bukhari, "Manaqibu al Anshar bab al Mi'raj”. VII.

Bell, Catherine. 1997. Ritual Perspective and Dimensions. New York : Oxford University Press.

Bakdasy, Said Muhammad dan Ibnu Hajar al Asqalani. 2002. Zam-zam: Sejarah, Legenda dan Khasiatnya. Diterjemahkan oleh M. Halaby Hamdi. Yogyakarta: Madani Pustaka Hikmah.

Cohan, Parcy S. 1969. Theories of Myth, dalam Man, The Journal of The Royal Anthropological Intitute, Vol. 4 No. 3 September. 
Djamhari. 1988. Agama dalam Perspektif Sosiologi. Jakarta: Departemen Pendidikan dan Kebudayaan Dirjen Dikti, Proyek Pengembangan lembaga Pendidikan Tenaga Kependidikan.

Dhavamony, Mariasusai. 1995. Fenomenologi Agama. Yogyakarta: IKAPI.

E. Bethe. 1987. Mythus-sage-marchen dalam Thomas F. Odea, The Sociology of Religion, Diterjemahkan oleh Tim Yosogama. Jakarta: PT. Raja Wali.

Hayat, Muhammad. 2003. Bertahannya Tradisi Tengger dalam Masyarakat Yang Sedang Berubah dalam Nuruddin dkk., Agama Tradisional: Potret Kearifan Hidup Masyarakat Samin dan Tengger. LkiS: Yogyakarta.

Ibad, Muhammad Nurul. 2007. Perjalanan dan Ajaran Gus Miek. Yogyakarta: LkiS.

Kirk, G.S. 1983. Myth Its Meaning $\mathcal{E}$ Functions in Ancient $\mathcal{E}$ Other Cultures. London: University of California Press.

Kuntowijoyo. 2002. Selamat Tinggal Mitos Selamat Datang Realitas. Bandung: Mizan.

Malinowski, Bronislow. 1954. Megic, Science and Religion. New York: Daubleday Anchor Book.

Malinowski, Bronislow. 1954. Myth in Primitive Psichology. dalam Magic, Science and Religion. New York.

Rasyid, Ahmad Zainuri. tt. Mambau al Hikmah Fi al Dzulumat wa al 'Ad'iyah wa al adwiyah. Kendal: Hizba.

Riyanto, Armada. 2002. Filsafat: Peradaban Rasionalitas. Makalah Universitas Muhammadiyah Malang.

Sunarto, Achmad. 1990. Syamsul Ma'arif: Perisai Mu'min dalam Kehidupan. Surabaya: Mutiara Ilmu.

Subagya, Rahmad, 1981. Agama Asli Indonesia . Sinar harapan: Jakarta.

Q S: $9:$ 72, 89, 100., Q.S: 10: 9., Q.S: 13: 4 dan 23., Q.S: 14: 23., Q.S: 15: 45., Q.S: $2: 25$.

el-Harakah, Vol. 12, No.2, Tahun 2010 